University of Wollongong

Research Online

Faculty of Engineering - Papers (Archive)

Faculty of Engineering and Information

Sciences

$1-11-2006$

\title{
Spherical Clusters of NiO Nanoshafts for Lithium-Ion Battery Anodes
}

L. Yuan

University of Wollongong

Z. P. Guo

University of Wollongong, zguo@uow.edu.au

Konstantin Konstantinov

University of Wollongong, konstan@uow.edu.au

P. Munroe

University of New South Wales

Hua-Kun Liu

University of Wollongong, hua@uow.edu.au

Follow this and additional works at: https://ro.uow.edu.au/engpapers

Part of the Engineering Commons

https://ro.uow.edu.au/engpapers/332

\section{Recommended Citation}

Yuan, L.; Guo, Z. P.; Konstantinov, Konstantin; Munroe, P.; and Liu, Hua-Kun: Spherical Clusters of NiO Nanoshafts for Lithium-Ion Battery Anodes 2006.

https://ro.uow.edu.au/engpapers/332

Research Online is the open access institutional repository for the University of Wollongong. For further information contact the UOW Library: research-pubs@uow.edu.au 


\title{
Spherical Clusters of NiO Nanoshafts for Lithium-Ion Battery
} Anodes

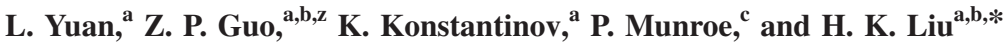 \\ ${ }^{a}$ Institute for Superconducting and Electronic Materials, and ${ }^{b} A R C$ Centre of Excellence for \\ Electromaterials Science, University of Wollongong, New South Wales 2522, Australia \\ ${ }^{c}$ Electron Microscopy Unit, University of New South Wales, Kensington, New South Wales 2033, Australia
}

\begin{abstract}
Spherical clusters of $\mathrm{NiO}$ nanoshafts were prepared using a simple, rapid, and easily scaled up method, i.e., chemical precipitation followed by thermal decomposition. The microstructural characteristics of spherical clusters of nanoshafts were examined by scanning electron microscopy, which showed that the $\mathrm{NiO}$ nanoshafts were arranged randomly on the surface of the spherical particles and had grown from the center of the spherical particles to their surface. The electrochemical properties of the assynthesized $\mathrm{NiO}$ nanoshaft clusters were investigated to determine their suitability as anode materials for lithium-ion batteries. The nanoshaft cluster electrodes exhibited better reversibility and higher capacities than $\mathrm{NiO}$ nanoparticle electrodes. The reasons for the improved electrochemical performance of the nanoshaft cluster electrodes are discussed.

(c) 2006 The Electrochemical Society. [DOI: 10.1149/1.2345550] All rights reserved.
\end{abstract}

Manuscript submitted June 1, 2006; revised manuscript received July 26, 2006. Available electronically September 8, 2006.

Rock salt structured MO-type $(\mathrm{M}=\mathrm{Fe}, \mathrm{Co}, \mathrm{Ni}, \mathrm{Cu}, \ldots)$ transition metal oxides react reversibly with lithium in a lithium cell below $1.5 \mathrm{~V} .{ }^{1}$ It has been reported that the MO type oxides demonstrate large capacity $(700 \mathrm{mAh} / \mathrm{g})$, long cycle life, and high recharging rates. These brilliant properties make them promising candidates for use as anode materials for Li-ion batteries. ${ }^{2}$ Among them, nickel oxide is an interesting material due to its applications in diverse fields, including catalysis, ${ }^{3}$ electrochromic films, ${ }^{4,5}$ fuel cell electrodes ${ }^{6,7}$ gas sensors, ${ }^{8,9}$ smart windows, ${ }^{10-12}$ and lithium-ion batteries. $^{13,14}$ Many methods have been used to prepare $\mathrm{NiO}$, such as calcinations of almost any nickel compounds in air, physical and chemical vapor deposition, and the sol-gel process. ${ }^{15-17}$ Considerable efforts have also been made in the synthesis of one-dimensional (1D) nanostructured $\mathrm{NiO}$ materials because of their intriguing properties and unique applications. Wang et al. ${ }^{18}$ synthesized single crystal cubic $\mathrm{NiO}$ nanorods by a simple thermal decomposition approach. Matsui et al. ${ }^{19}$ made nickel oxide nanoribbons in the cavities of carbon nanotubes. Polycrystalline $\mathrm{NiO}$ nanowires have been synthesized by an electrochemical deposition method, ${ }^{20}$ while single crystal $\mathrm{NiO}$ nanowires have been prepared via a wet chemical method, a molten salt assisted oxidation route, and a sol-gel process. $16,21,22$

In this paper, we report a simple aqueous solution method in combination with calcination to fabricate spherical clusters of $\mathrm{NiO}$ nanoshafts. For comparison, $\mathrm{NiO}$ nanoparticles made by calcining $\mathrm{Ni}(\mathrm{OH})_{2}$ nanopowder were also prepared. Although $\mathrm{NiO}$ nanopowders, nanotubes, and thin films have been reported recently as anode materials for lithium-ion batteries, ${ }^{13,14,23,24} \mathrm{NiO}$ spherical particles composed of nanoshafts have not been reported to the best of our knowledge. Because both the morphology and the particle size of transition-metal oxides ( $\mathrm{MO}$, where $\mathrm{M}$ is $\mathrm{Fe}, \mathrm{Co}, \mathrm{Ni}, \mathrm{Cu}$, or $\mathrm{Mn}$ ) have an influence on their anode performance, ${ }^{1,25}$ this investigation on the spherical clusters of $\mathrm{NiO}$ nanoshafts has some significance. The advantages of the spherical clusters of $\mathrm{NiO}$ nanoshafts as anode materials for lithium-ion batteries are not only the extremely large surface area, but also that it is easy for the lithium ions to diffuse along the direction of the nanoshafts.

The electrochemical performance of the as-prepared spherical clusters of $\mathrm{NiO}$ nanoshafts and $\mathrm{NiO}$ nanoparticles as anode materials for lithium-ion batteries was systematically investigated by using cyclic voltammetry $(\mathrm{CV})$ and charge/discharge methods. The results show that spherical clusters of $\mathrm{NiO}$ nanoshafts are promising materials for application in rechargeable lithium-ion batteries.

\footnotetext{
* Electrochemical Society Active Member

ż-mail: zguo@uow.edu.au
}

\section{Experimental}

Materials preparation.- Preparation of nanoshaft clusters.Spherical clusters of $\mathrm{NiO}$ nanoshafts were synthesized by decomposing (at $280^{\circ} \mathrm{C}$ in air) spherical $\mathrm{Ni}(\mathrm{OH})_{2}$ precursors. The preparation of the precursor is the most crucial step in the synthesis procedure. First, nickel sulfate was dissolved in distilled water; then $\mathrm{NH}_{3} \cdot \mathrm{H}_{2} \mathrm{O}$ was added to the $\mathrm{NiSO}_{4}$ solution as a complexing agent. The $\mathrm{pH}$ was adjusted to 11-12. After that, sodium hydroxide solution was dropped into the reaction solution very slowly, and precipitation was induced. The temperature of the reaction solution was maintained at about $45^{\circ} \mathrm{C}$, while the reaction solution was continuously stirred. Throughout this operation, the $\mathrm{pH}$ and temperature of the reaction solution were rigidly kept at values within the abovementioned ranges. Thus, spherical $\mathrm{Ni}(\mathrm{OH})_{2}$ particles were yielded. The next step consisted of the calcination of the $\mathrm{Ni}(\mathrm{OH})_{2}$ precursors. To preserve the morphology of the precursors, we needed to optimize the calcination parameters. Thermogravimetric analysis/ differential thermal analysis (TGA/DTA) on the precursors was conducted at a heating rate of $5^{\circ} \mathrm{C} \mathrm{min}-1$ in air. The TGA/DTA curves showed that the decomposition of the hydroxide precursor occurs between 240 and $320^{\circ} \mathrm{C}$. Therefore, in our work, we chose to calcine the precursor at $280^{\circ} \mathrm{C}$ for $2 \mathrm{~h}$ in air.

Preparation of $\mathrm{NiO}$ nanoparticles. - $\mathrm{NiO}$ nanoparticles were also prepared for comparison. $\mathrm{NiO}$ nanoparticles were prepared by grinding a stoichiometric amount of $\mathrm{Ni}(\mathrm{OAc})_{2} \cdot 4 \mathrm{H}_{2} \mathrm{O}$ with $\mathrm{KOH}$ and the appropriate amount of citric acid in an agate mortar at room temperature for about $30 \mathrm{~min}$. Then, the products were washed with distilled water, treated in an ultrasonic bath with ethanol, and centrifuged. After that, the samples were dried at $80^{\circ} \mathrm{C}$ in vacuum for $4 \mathrm{~h}$, and a light green $\mathrm{Ni}(\mathrm{OH})_{2}$ powder was obtained, which was then sintered at $350^{\circ} \mathrm{C}$ for $2 \mathrm{~h}$.

Materials characterization.- Powder X-ray diffraction (1730 Philips X-ray diffractometer) using $\mathrm{Cu} \mathrm{K} \alpha$ radiation was employed to identify the crystalline phase of the synthesized materials. The morphology of the resulting powders was observed using a scanning electron microscope (SEM) (JEOL JSM-6460A instrument).

Coin cells were assembled for electrochemical characterization of $\mathrm{NiO}$ electrodes. The test electrodes were made by dispersing 80 wt $\%$ active materials, $10 \mathrm{wt} \%$ carbon black, and $10 \mathrm{wt} \%$ polyvinylidene fluoride (PVDF) binder in dimethyl phthalate solvent to form a slurry. The slurry was then spread on copper foil substrates. The coated electrodes were dried in a vacuum oven at $100^{\circ} \mathrm{C}$ for $20 \mathrm{~h}$ and then pressed. After drying, the electrodes were cut to a $1 \times 1 \mathrm{~cm}$ size. CR 2032 coin-type cells were assembled in an Arfilled glove box (Mbraun, Unilab, Germany). The electrolyte was $1 \mathrm{M} \mathrm{LiPF}_{6}$ in a mixture of ethylene carbonate (EC) and dimethyl carbonate (DMC) (1:1 by volume, provided by Merck KgaA, Ger- 


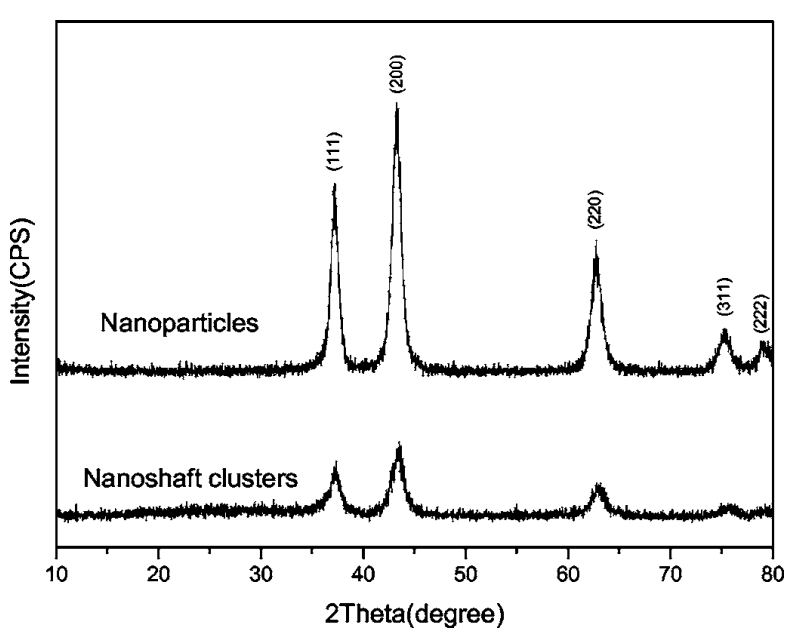

Figure 1. XRD patterns of the as-prepared $\mathrm{NiO}$ materials.

many). The cells were galvanostatically charged and discharged at $50 \mathrm{~mA} / \mathrm{g}$ over a voltage range of $0.01-3.0 \mathrm{~V}$ vs $\mathrm{Li} / \mathrm{Li}^{+}$. CV measurements were carried out on a potentiostat (model M362, EG\&G Princeton Applied Research, USA) at a scanning rate of $0.5 \mathrm{mV} / \mathrm{s}$.

\section{Results and Discussion}

Characterization of nanomaterials. - The spherical clusters of $\mathrm{NiO}$ nanoshafts were synthesized by decomposing spherical clusters of $\mathrm{Ni}(\mathrm{OH})_{2}$ nanoshafts at $280^{\circ} \mathrm{C}$ in air. Despite full conversion to the ordered cubic unit cell, the overall morphology of the spherical clusters of nanoshafts has remained. We believe that the main difference between our preparation method and others lies in the strict control of the speed at which the sodium hydroxide and ammonia aqueous solution are added, the $\mathrm{pH}$ values, and the reaction temperature. The $\mathrm{NH}_{3} \cdot \mathrm{H}_{2} \mathrm{O}$ works as a complexing agent, helping to form 1D $\mathrm{Ni}(\mathrm{OH})_{2}$ nanoshaft structures, which is believed to be beneficial to formation of agglomerated particles with an overall spherical shape. ${ }^{26}$ The phase purity and crystallinity of the as-synthesized $\mathrm{NiO}$ materials were characterized by using XRD. Figure 1 shows the XRD patterns of the as-prepared spherical clusters of $\mathrm{NiO}$ nanoshafts and nanoparticles. All diffraction peaks can be perfectly indexed to cubic structure crystalline $\mathrm{NiO}$, indicating that there is no impurity in the $\mathrm{NiO}$ powder. The Bragg peaks of the spherical clusters of $\mathrm{NiO}$ nanoshafts are markedly broadened compared with those of the $\mathrm{NiO}$ nanoparticles, suggesting that very fine grain sizes and defects in the spherical clusters of $\mathrm{NiO}$ nanoshafts were produced in the synthesizing process. The crystallite size of $\mathrm{NiO}$ was calculated using the Scherrer equation, and the calculated crystallite sizes of $\mathrm{NiO}$ in the as-prepared spherical clusters of $\mathrm{NiO}$ nanoshafts and $\mathrm{NiO}$ nanoparticles are 6.73 and $10.71 \mathrm{~nm}$, respectively.

Figure 2 shows scanning electron microscope (SEM) images of the as-prepared spherical clusters of $\mathrm{NiO}$ nanoshafts. Figure $2 \mathrm{a}$ is an overall view of the as-synthesized spherical clusters, from which it can be seen that the aggregated nanoshafts are spherical in morphology with particle sizes ranging from less than $3 \mu \mathrm{m}$ to greater than $10 \mu \mathrm{m}$. Figure $2 \mathrm{~b}$ shows a typical surface image of the spherical particles at a higher magnification. This shows that $\mathrm{NiO}$ nanoshafts are arranged randomly on the surface of the spherical particles. Figure $2 \mathrm{c}$ shows the particle surface at an even higher magnification. The primary NiO nanoshafts show that the diameter of the shafts becomes smaller along the length of the particles and finally forms nanoscale tips. The interior of the spherical particles was also investigated (as shown in Fig. 3d). From the crack on the surface of the spherical particle, it can be seen that the nanoshafts grow also from the center of the spherical particles to their surface. Note that the
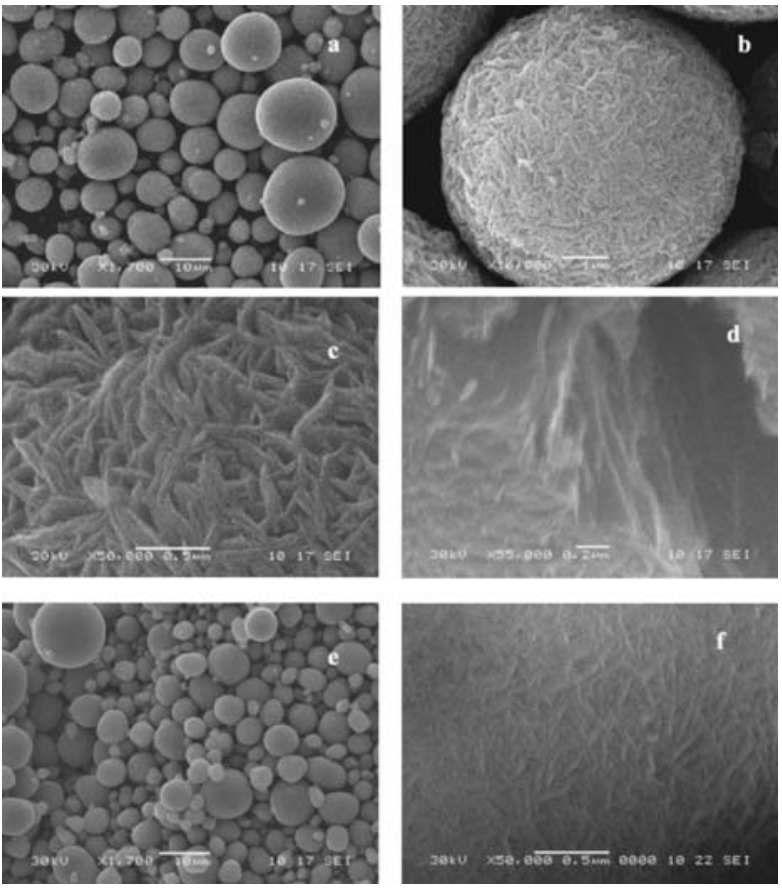

Figure 2. SEM images of the spherical clusters of NiO nanoshafts (a) at low magnification, (b) at high magnification (surface of a spherical particle), (c) at higher magnification (surface of a spherical particle), and (d) in a cracked $\mathrm{NiO}$ spherical particle. (e) SEM images of the spherical $\mathrm{Ni}(\mathrm{OH})_{2}$ precursor at low magnification and (f) at higher magnification.

spherical clusters of nanocrystals could also serve as effective confined templates for spherical nanostructures. The morphologies of these spherical clusters can be maintained even after thermal treatment at $1000^{\circ} \mathrm{C}$ (Fig. 3). However, the primary $\mathrm{NiO}$ nanoshaft structure in the spherical particles is destroyed, and submicrometer-sized particles are formed. These submicrometer-sized particles are ar-

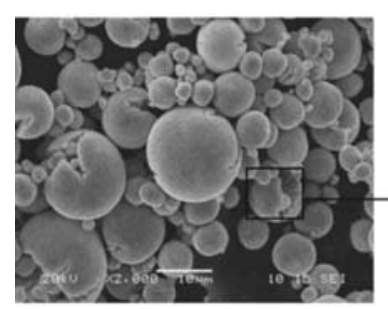

(a)

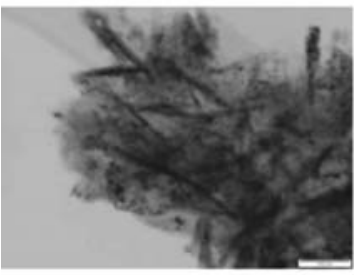

(c)

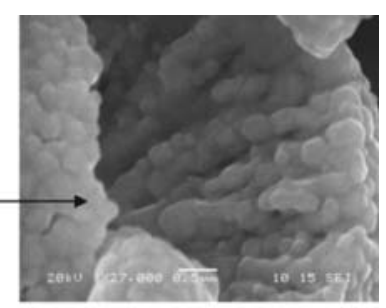

(b)

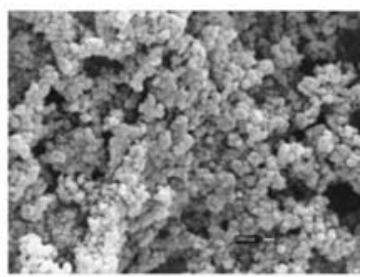

(d)
Figure 3. SEM images of the spherical $\mathrm{NiO}$ following calcination for $3 \mathrm{~h}$ at $1000^{\circ} \mathrm{C}$ (a) at low magnification and (b) at higher magnification. (c) TEM of the NiO nanoshafts and (d) SEM of NiO nanoparticles. 

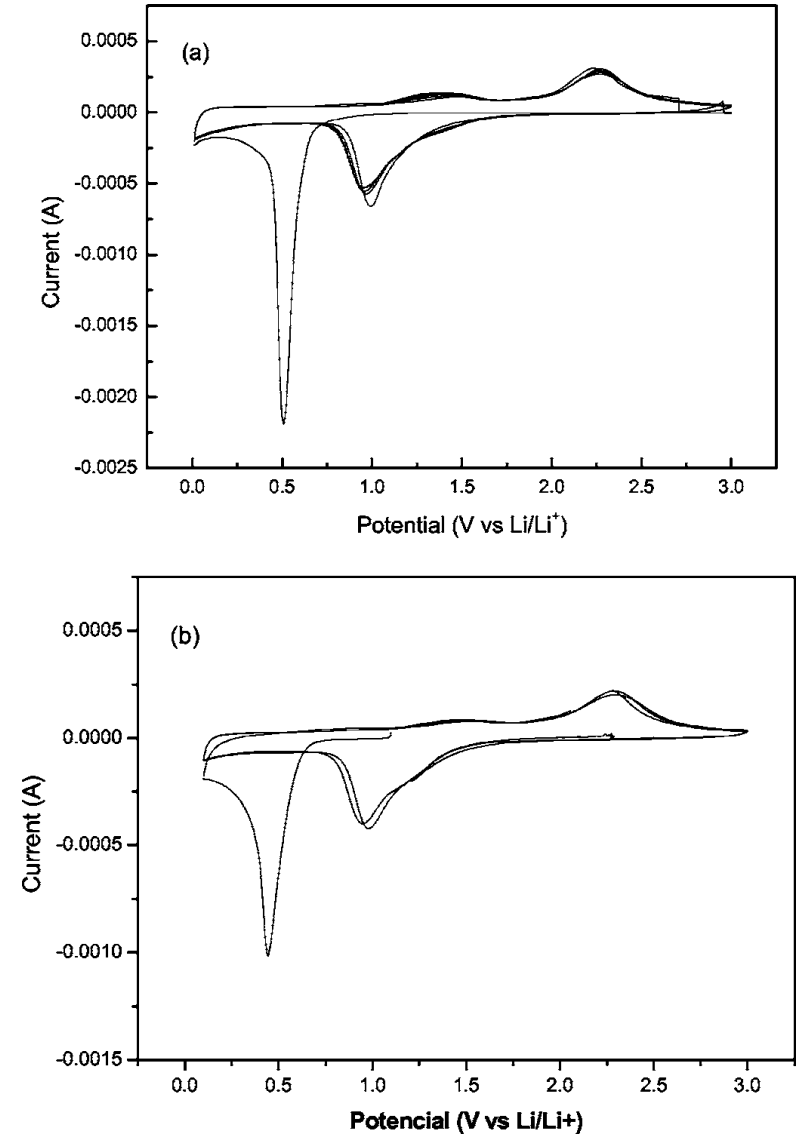

Figure 4. $\mathrm{CV}$ s of electrodes made with $\mathrm{NiO}$ (a) nanoshaft clusters and (b) nanoparticles.

ranged in an ordered way (as shown in Fig. 3b), which reflects the original structure of the spherical particles before heat-treatment. Figure $3 \mathrm{c}$ is the bright-field TEM image of some NiO nanoshaft clusters. The material was ground in an agate mortar before TEM sample preparation. It is obvious that some nanoshaft structures have been destroyed during grinding. However, nanoshafts with lengths of 100-400 nm still can be observed. Figure 3d shows a typical image of $\mathrm{NiO}$ nanoparticles, from which it can be seen that the sample is composed of nanoparticles with typical sizes of about $100 \mathrm{~nm}$. Brunauer-Emmett-Teller (BET) nitrogen-adsorption measurements show that the specific surface areas of the NiO nanoshaft clusters and nanoparticles are 113 and $36 \mathrm{~m}^{2} / \mathrm{g}$, respectively.

Electrochemical characterizations.-Figure 4a shows CVs of electrodes made from spherical clusters of $\mathrm{NiO}$ nanoshafts. For comparison, the $\mathrm{CV}$ curves of $\mathrm{NiO}$ nanoparticle electrode are also shown in Fig. 4b. The profiles of CV curves for both electrodes are similar, but differences between the first and subsequent cycles are found in the $\mathrm{CV}$ curves. A reduction peak ranging from $0.3-0.8 \mathrm{~V}$ in the first cycle corresponds to the initial reduction of $\mathrm{NiO}$ to metallic $\mathrm{Ni}$ nanoparticles and the formation of a partially reversible solid electrolyte interface (SEI) layer. In the subsequent cycles, the reduction peak becomes broad and is composed of a main peak at around $0.98 \mathrm{~V}$ and a low-density shoulder peak near $1.3 \mathrm{~V}$. In the oxidation scan, two broad peaks are well resolved at about 1.3 and $2.2 \mathrm{~V}$. The two pairs of redox peaks indicate that there are two sets of faradaic reaction involved. The well-known mechanisms for these reactions are the reversible reaction of $\mathrm{NiO} \Leftrightarrow \mathrm{Ni} / \mathrm{Li}_{2} \mathrm{O}$ and the partial composition/decomposition of the polymeric coating on the $\mathrm{NiO}$ surface. $^{27,28}$ By carefully comparing the CV curves of spherical clusters of $\mathrm{NiO}$ nanoshafts with those of $\mathrm{NiO}$ nanoparticles, it was found that the potential and the current densities of peaks are different. The results describing the features of the second cycle $\mathrm{CV}$ curves are summarized in Table I. From Table I, it is found that in the second cycle, the current densities for the nanoshaft cluster electrode are much larger than for the nanoparticle electrode, revealing higher capacity and faster kinetics for the $\mathrm{Ni}^{2+} / \mathrm{Ni}$ transformation in the nanoshaft cluster electrode. In addition, for the nanoshaft cluster electrode, the potential difference between $E_{\mathrm{O} 2}$ and $E_{\mathrm{r} 2}$ $(2.245-0.994=1.251 \mathrm{~V})$, which corresponds to the redox reaction $\mathrm{NiO} \Leftrightarrow \mathrm{Ni} / \mathrm{Li}_{2} \mathrm{O}$, is smaller than that of the nanoparticle electrode $(2.274-0.979=1.295 \mathrm{~V})$, indicating the higher reversibility and better stability of the nanoshaft cluster electrode. A decrease in the individual peak intensity and integral areas for $E_{\mathrm{O} 2}$ and $E_{\mathrm{r} 2}$ with cycling are also observed for both electrodes, with $E_{\mathrm{O} 2}$ shifting to higher potential while $E_{\mathrm{r} 2}$ shifts to a lower potential. The decrease in the peak density and integral areas results from the irreversible capacity losses due to the incomplete redox reaction. The increase in the potential difference $\left(E_{\mathrm{O} 2}-E_{\mathrm{r} 2}\right)$ with cycling indicates degradation of the electrodes. However, the shape of the CV curves in the following cycles remained similar to those in the second cycle, suggesting reversible reduction and oxidation of the $\mathrm{NiO}$ electrode materials

The voltage-specific capacity profiles of the $\mathrm{NiO} / \mathrm{Li}$ cells were obtained using constant current charge/discharge measurements. Figure 5 shows the first two charging/discharging curves of the electrodes made from $\mathrm{NiO}$ nanoshaft clusters and nanoparticles, which were measured between 0.01 and $3.0 \mathrm{~V} \mathrm{vs} \mathrm{Li} / \mathrm{Li}^{+}$at a current density of $50 \mathrm{~mA} / \mathrm{g}$ and room temperature. In the first discharge, the potential drops rapidly to reach a well-pronounced plateau at about $0.7 \mathrm{~V}$, followed by a gradual decrease to $0.01 \mathrm{~V}$. The discharge capacity delivered is above $1300 \mathrm{mAh} / \mathrm{g}$, which is higher than the theoretical capacity $(718 \mathrm{mAh} / \mathrm{g})$. It is possible that the extra capacity was contributed by the formation of a polymer-like SEI. ${ }^{23,24}$ The well-resolved oxidation peak $\left(E_{\mathrm{O} 1}\right)$ in the CV curves (Fig. 4) is evidence for this. The first charge proceeds with a higher voltage and less capacity. In the second discharge, the plateau appears at about $1.1 \mathrm{~V}$, which is related to the reduction process $E_{\mathrm{r} 2}$ in Fig. 4. The subsequent charge plateaus appear at about 1.3 and $2.2 \mathrm{~V}$, which correspond to the two oxidation peaks $\left(E_{\mathrm{o} 1}\right.$ and $\left.E_{\mathrm{o} 2}\right)$ in Fig. 4. By careful comparison, it is found that the discharge curves of the nanoshaft cluster electrode exhibit a higher discharging voltage and a longer plateau than those of the nanoparticle electrode, indicating a higher power-output behavior.

Figure 6 shows the curves of specific capacity vs cycle number

Table I. Reduction potentials $\left(E_{\mathrm{r} 1}, E_{\mathrm{r} 2}\right)$, oxidation potential $\left(E_{01}, E_{02}\right)$, and the corresponding current densities of the electrodes made with NiO nanoshaft clusters and nanoparticles in the second cycle $\mathrm{CV}$ curves.

\begin{tabular}{|c|c|c|c|c|c|c|c|c|}
\hline \multirow{2}{*}{$\begin{array}{c}\mathrm{NiO} \\
\text { electrode }\end{array}$} & \multicolumn{4}{|c|}{ Potential values (V) } & \multicolumn{4}{|c|}{ Current densities $\left(\mathrm{mA} \mathrm{cm}^{-2}\right)$} \\
\hline & $E_{\mathrm{r} 1}$ & $E_{\mathrm{r} 2}$ & $E_{\mathrm{o} 1}$ & $E_{\mathrm{o} 2}$ & $I\left(E_{\mathrm{r} 1}\right)$ & $I\left(E_{\mathrm{r} 2}\right)$ & $I\left(E_{\mathrm{o} 1}\right)$ & $I\left(E_{\mathrm{o} 2}\right)$ \\
\hline Nanoshaft clusters & 1.378 & 0.994 & 1.311 & 2.245 & 0.142 & 0.646 & 0.143 & 0.324 \\
\hline Nanoparticles & 1.287 & 0.979 & 1.408 & 2.274 & 0.097 & 0.405 & 0.086 & 0.223 \\
\hline
\end{tabular}



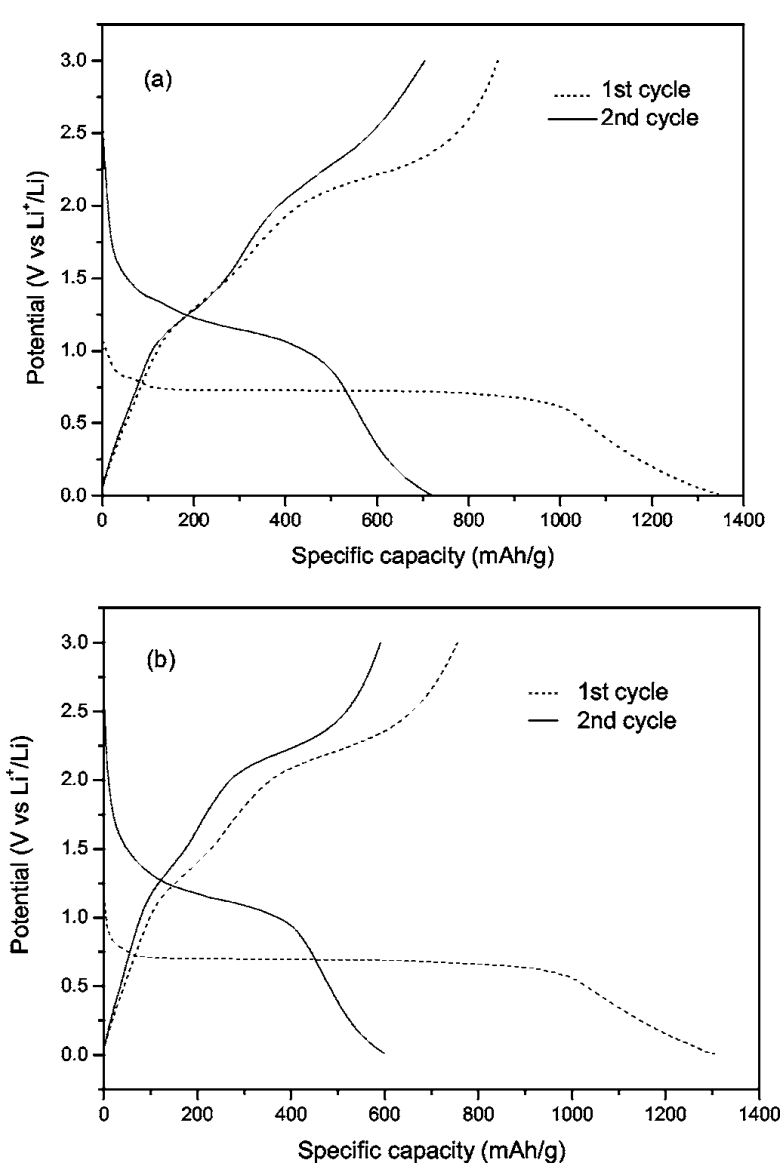

Figure 5. Charge/discharge curves of the electrodes made with the asprepared (a) $\mathrm{NiO}$ nanoshaft clusters and (b) $\mathrm{NiO}$ nanoparticles.

for the electrodes made from $\mathrm{NiO}$ nanoshaft clusters and nanoparticles. Generally, the reversible capacity decreased with cycling. The capacity fading rate became faster after 16 cycles. After 30 cycles, the nanoshaft cluster and nanoparticle electrodes maintained 410 and $203 \mathrm{mAh} / \mathrm{g}$, corresponding to about $47.8 \%$ and $26.9 \%$ of the initial capacity, respectively, indicating that the morphology has an influence on the electrode cycling stability.

By comparing the electrochemical behavior of the as-prepared $\mathrm{NiO}$ electrode with other reported transition metal oxide electrodes, such as $\mathrm{CoO}, \mathrm{CuO}, \mathrm{Co}_{3} \mathrm{O}_{4}$, and $\mathrm{Fe}_{2} \mathrm{O}_{3}$, it is found that the cycling performance of the as-prepared $\mathrm{NiO}$ electrode (with capacity after 20 cycles $64.1 \%$ of the initial capacity) is comparable to that of $\mathrm{Fe}_{2} \mathrm{O}_{3}$ nanotube electrode $(62.9 \%){ }^{29}$ while the capacity decays faster than $\mathrm{CoO}, \mathrm{CuO}$, or $\mathrm{Cu}_{2} \mathrm{O}$ electrode. However, the as-prepared $\mathrm{NiO}$ electrode has a higher reversible capacity than $\mathrm{CuO}$ and $\mathrm{Cu}_{2} \mathrm{O},{ }^{1,2}$ and it is less expensive than $\mathrm{CoO}$ and $\mathrm{Co}_{3} \mathrm{O}_{4}$. The charge/ discharge curves of the $\mathrm{MO}$ electrodes $(\mathrm{M}=\mathrm{Co}, \mathrm{Ni}, \mathrm{Fe}$ etc.) show some similarities. During the first discharge, the potential rapidly drops to a plateau, and then continuously decreases down to lower potential. The second discharge curve differs significantly from the first one, indicating structural or textural modifications. Poizot et al. have proposed a new electrochemical mechanism for these transition-metal oxide electrodes, which can be written as

$$
\mathrm{M}_{x} \mathrm{O}_{y}+2 y \mathrm{Li} \leftrightarrow y \mathrm{Li}_{2} \mathrm{O}+x \mathrm{M}
$$

During the discharge, the $\mathrm{M}_{x} \mathrm{O}_{y}$ particles are reduced into highly dispersed metallic nanoparticles and $\mathrm{Li}_{2} \mathrm{O}$, but the overall shape of

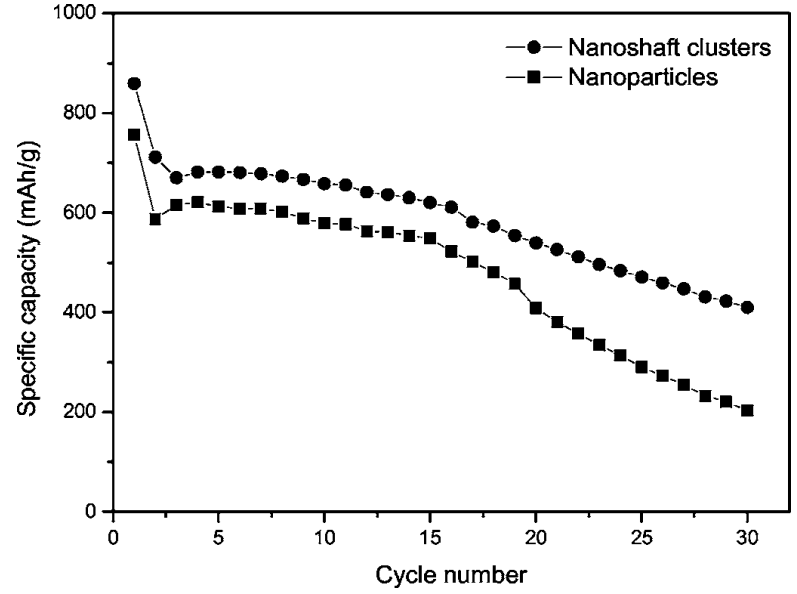

Figure 6. Capacity as a function of cycle number for the electrodes made with the as-prepared $\mathrm{NiO}$ nanoshaft clusters and the $\mathrm{NiO}$ nanoparticles.

the starting particle is preserved. During the subsequent charge, the $\mathrm{Li}_{2} \mathrm{O}$ matrix decomposes and $\mathrm{M}$ nanoparticles convert back to $\mathrm{M}_{x} \mathrm{O}_{y}$ nanograins.

According to the results presented above, the electrochemical performance of electrodes made with spherical clusters of $\mathrm{NiO}$ nanoshafts is better than that of nanoparticle electrodes. This may be due to the high surface-to-volume ratio of the spherical clusters of $\mathrm{NiO}$ nanoshafts. The highly nanoporous structure of the spherical clusters contributes to a higher specific surface area $\left(113 \mathrm{~m}^{2} / \mathrm{g}\right)$, making the electrochemical reaction with lithium more effective. On the other hand, the nanoshaft structures are favorable for the diffusion of lithium ions, providing more active sites. In addition, the spherical cluster structure may prohibit aggregation of Ni crystals to some extent, relieving the stress caused by volume change during the charge/discharge cycles, and thereby suppressing the degradation of the $\mathrm{NiO}$ electrode. Further study on electrode materials after charge/discharge cycling and at different charge/discharge states by TEM, high-resolution TEM, and XPS is necessary to verify this assumption. This aspect of the work is ongoing in our laboratory, and the results will be published elsewhere.

\section{Conclusions}

Spherical clusters of $\mathrm{NiO}$ nanoshafts were successfully prepared by chemical precipitation followed by precursor decomposition at $280^{\circ} \mathrm{C}$ in air. Electrochemical measurements showed that the asprepared nanoshaft cluster electrodes could be charged and discharged reversibly with high capacities and superior cycling reversibility. In view of this special structural arrangement, it is proposed that redox reactions with $\mathrm{Li}$ could be more efficiently conducted with the spherical NiO nanoshaft clusters than with their nanocrystalline counterparts. The enhanced electrochemical character of nanoshaft cluster electrodes arises from their relatively high specific surface areas and easier lithium diffusion. Therefore, spherical clusters of $\mathrm{NiO}$ nanoshafts are promising materials for application in rechargeable lithium-ion batteries.

\section{Acknowledgments}

Financial support from the Australian Research Council is gratefully acknowledged.

The University of Wollongong assisted in meeting the publication costs of this article.

\section{References}

1. P. Poizot, S. Laruelle, S. Grugeon, L. Dupont, and J.-M. Tarascon, Nature (London), 407, 496 (2000). 
2. P. Poizot, S. Laruelle, S. Grugeon, and J.-M. Tarascon, J. Electrochem. Soc., 149, A1212 (2002).

B. Sheela, H. Gomathi, and G. P. Rao, J. Electroanal. Chem., 394, 267 (1995).

4. M. Chigane and M. Ishikawa, J. Chem. Soc., Faraday Trans., 88, 2203 (1992)

4. M. Chigane and M. Ishikawa, J. Chem. Soc., Faraday Trans., 88, 2203 (1992).

5. K. Yosh

. P. Tomczyk, G. Mordarshi, and J. Oblakowski, J. Electroanal. Chem., 353, 177 (1993).

7. C. R. Makkus, K. Hemmes, and D. W. Wir, J. Electrochem. Soc., 141, 3429 (1994)

8. B. C. Alcock, Z. Li, W. J. Fergus, and L. Wang, Solid State Ionics, 39, 53 (1992).

9. H. Kumagai, M. Matsumoto, K. Toyoda, and M. Obara, J. Mater. Sci. Lett., 15 1081 (1996).

10. F. F. Ferreira, M. H. Tabacnikes, M. C. A. Fantini, I. C. Faria, and A. Gorenstein, Solid State Ionics, 86-88, 971 (1996).

11. J. Scarminio, A. Urbano, B. J. Gardes, and A. Gorenstein, J. Mater. Sci. Lett., 562 11 (1992).

12. M. C. A. Fantini, G. H. Benerra, C. R. C. Carvalho, and A. Gorenstein, Proc. SPIE, 1536, 81 (1996)

13. K.-F. Chiu, C. Y. Chang, and C. M. Lin, J. Electrochem. Soc., 152, A1188 (2005)

14. Y. Wang and Q. Z. Qin, J. Electrochem. Soc., 149, A873 (2002).

15. Z. Jiao, M. Wu, Z. Qin, and H. Xu, Nanotechnology, 14, 458 (2003).
16. Q. Yang, J. Sha, X. Ma, and D. Yang, Mater. Lett., 59, 1967 (2005).

17. I. W. Lenggoro, Y. Itoh, N. Iida, and K. Okuyama, Mater. Res. Bull., 38, 1819 (2003).

18. W. Wang, Y. Lin, and C. Xu, Chem. Phys. Lett., 362, 199 (2002).

19. K. Matsui, B. K. Pradhan, T. Kyotani, and A. Tomita, J. Phys. Chem. B, 105, 5682 (2001).

20. Y. Lin, T. Xie, B. Cheng, B. Geng, and L. Zhang, Chem. Phys. Lett., 380, 521 (2003).

21. C. Xu, K. Hong, S. Liu, G. Wang, and X. Zhao, J. Cryst. Growth, 255, 308 (2003).

22. Y. Zhan, C. Zhwng, Y. Liu, and G. Wang, Mater. Lett., 57, 3265 (2003)

23. X. H. Huang, J. P. Tu, B. Zhang, C. Q. Zhang, Y. Li, Y. F. Yuan, and H. M. Wu, J. Power Sources, In press.

24. S. A. Needham, G. X. Wang, and H. K. Liu, J. Power Sources, In press.

25. W. Y. Li, L. N. Xu, and J. Chen, Adv. Funct. Mater, 15, 851 (2005).

26. X. Mi, X. P. Gao, C. Y. Jiang, M. M. Feng, J. Yan, and C. R. Wan, Electrochim. Acta, 49, 3361 (2004).

27. S. Laruelle, S. Grugeon, P. Poizot, M. Dolle, L. Dupont, and J.-M. Tarascon, J. Electrochem. Soc., 149, A627 (2002)

28. M. Dolle, P. Poizot, L. Dupont, and J.-M. Tarascon, Electrochem. Solid-State Lett., 5. A18 (2002)

29. J. Chen, L. Xu, W. Li, and X. Gou, Adv. Mater. (Weinheim, Ger.), 17, 582 (2005). 